JPE 10-4-14

\title{
A General Purpose Inverter Set-Up for Power Electronics Laboratory Experiments
}

\author{
Mustafa Erman Kayakesen* and Isik Çadirci ${ }^{\dagger}$ \\ ${ }^{\dagger *}$ Dept. of Electrical and Electronics Eng., Hacettepe University, Ankara, Turkey
}

\begin{abstract}
A general purpose experimental set-up has been designed and implemented for students to carry out various experiments on inverters in the power electronics laboratories of universities, during a few hours of laboratory work. This is the first inverter setup that incorporates hardware and software control, as well as an optional user interface in a laboratory experimental set-up of a single multi-purpose inverter, thus making the system versatile and very practical for both undergraduate and graduate students. The system can be controlled either by a computer or through a liquid crystal display (LCD) and a keypad control unit, and it constitutes a low-cost alternative to relatively expensive commercial teaching sets. The computer provides a user friendly interface and easier control for laboratory environments equipped with computers. The LCD and keypad units eliminate the need for a computer, which makes this system usable in the laboratory as a standalone unit as well.
\end{abstract}

Key Words: Inverter control, Laboratory set-up, Microcontroller, Power electronics

\section{INTRODUCTION}

Inverter circuits constitute one of the most widely used power electronics converters in both industrial and domestic applications. The main function of an inverter is to convert DC power to AC power at a certain voltage magnitude and frequency depending on the requirements of the application by using different switching techniques such as squarewave, pulse-width modulation (PWM), phase-shifted PWM, and sinusoidal PWM (SPWM). There are lots of industrial application areas for inverters such as AC motor drives, uninterruptible power supplies, switch mode power supplies, active power filters, static VAr compensation systems, etc. Also, inverters are increasingly being used in energy saving applications such as heating, air conditioning and ventilation, as well as renewable energy conversion systems such as wind turbines, fuel-cell power conditioners etc. Thus, teaching about inverters at the undergraduate level has become an important task. However, this is a difficult task, due to the need for different controllers, and changing hardware requirements among different applications.

Laboratory work and practical classes play a major role in power electronics education [1]. The laboratory equipment used for this purpose should be simple, and practical [1]. By using a new methodological approach [2] to teaching power electronics converter experiments, instructors have seen a noticeable increase in student interest in the subject. Similarly, the concept of "Self-Learning" [3] motivates students to attend

\footnotetext{
Manuscript received Feb. 16, 2010; revised May 16, 2010

$\dagger$ Corresponding Author: cadirci@ee.hacettepe.edu.tr

Tel: +90-312-297-70-69, Fax: +90-312-299-21-25, Hacettepe Univ.

* Dept. of Electrical and Electronics Eng., Hacettepe Univ., Turkey
}

the laboratory. Using computer simulation technologies [4], and reducing practical hazards [5] are other fundamental issues in such laboratory experiments.

The general purpose experimental set-up developed in this work aims at making inverter experiments easily applicable during a few hours of laboratory work, as well as easier to understand for students. It is both versatile and low cost. The proposed system does not require any extra hardware, and incorporates ready to use, extendable software, which makes it directly applicable to various experiments, and graduate level system developments. This system has the option of being used as a standalone unit, without the necessity for a computer. Furthermore, in use with a computer, it provides the additional facility of displaying the expected signal waveforms on the same set-up, via built-in simulation software. This can be done before operating the system.

\section{SYSTEM DESCRIPTION}

The developed system has three main parts as illustrated in Fig. 1. These are the user interface, the control unit, and the power circuit. An insulated gate bipolar transistor (IGBT) based converter [6] is used as a part of the experimental set-up. The system can be controlled either by a computer, or through a $2 \times 16$ character LCD and a $4 \times 4$ keypad unit.

The control unit is used to set the process parameters such as the frequency, the duty cycle and the process mode type. Students can define these parameters using either a LCD and keypad or a computer. The control unit then implements the chosen process according to the set values of the parameters.

Fig. 2 depicts the system functions and their required parameters. The set-up can be used in both single-phase and 


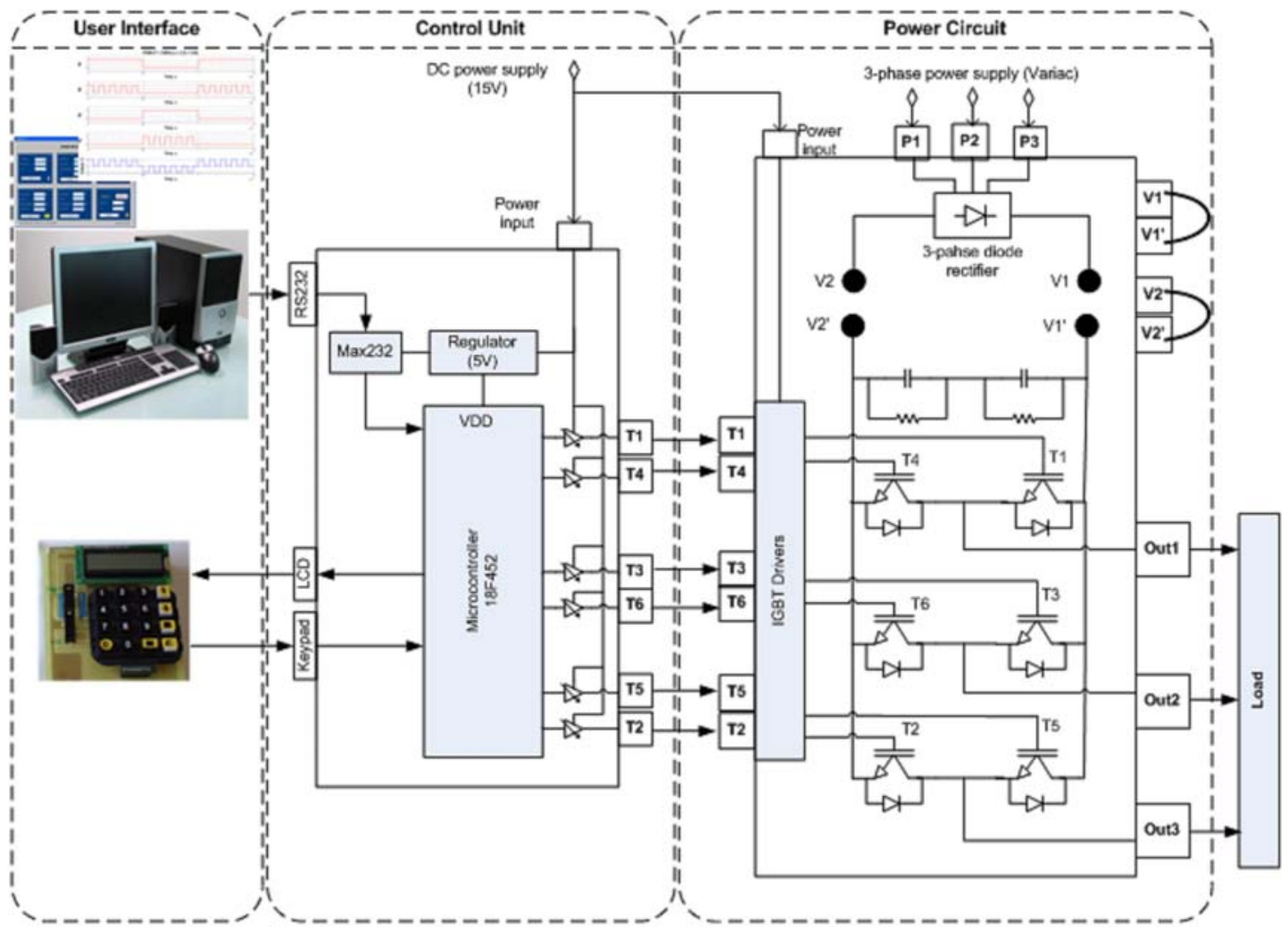

Fig. 1. Schematic diagram of the overall system.

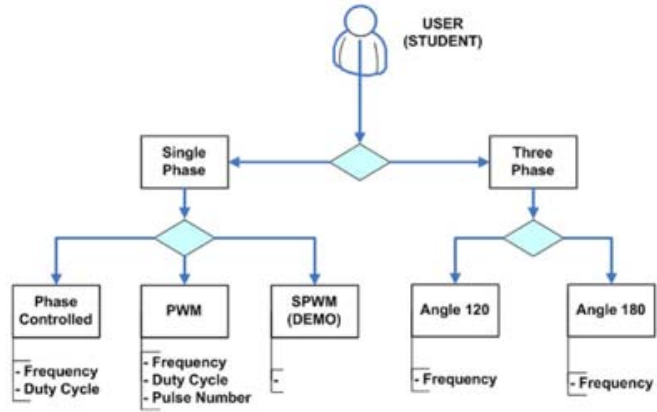

Fig. 2. The system functions and their required parameters.

three-phase systems.

For single-phase applications, three types of processes can be chosen; these are PWM, phase-shifted PWM, and SPWM. For three-phase applications, there are two types of processes; the $120^{\circ}$ conduction angle and the $180^{\circ}$ conduction angle controls. The system can operate satisfactorily over a wide range of frequencies between $1 \mathrm{~Hz}$ and $10 \mathrm{kHz}(5 \mathrm{kHz}$ for three phase control), with a $1 \mathrm{~Hz}$ resolution. Students can make two main decisions on the number of phases and on the process type. The frequency, duty cycle, and pulse number are optional parameters. Students can use these parameters as default values or adjust them by the use of a LCD and keypad.

The technical specifications of the developed system are given in Table I. The hardware design of the set-up, the software implementation, and the user interface are explained in detail in Section III.

TABLE I

TECHNICAL SPECIFICATIONS

\begin{tabular}{|c|c|}
\hline Q Quantity & Specification \\
\hline Microcontroller & PIC18F452, $40 \mathrm{MHz}$ \\
\hline Power supply & 15V, 14A SMPS \\
\hline LCD & $2 \times 16$ characters \\
\hline Keypad & $4 \times 4$ classical type \\
\hline Control type & $\begin{array}{l}\text { Microcontroller based via LCD \& } \\
\text { keypad or computer }\end{array}$ \\
\hline Inverter system & $\begin{array}{l}\text { Semiteach IGBT converter set } \\
\text { (Semiteach, 2005) }\end{array}$ \\
\hline $\begin{array}{l}\text { Inverter operating } \\
\text { frequency }\end{array}$ & $\begin{array}{l}\text { Adjustable: } 1 \mathrm{~Hz}-10 \mathrm{kHz} \\
(1 \mathrm{~Hz}-5 \mathrm{kHz} \text { for three-phase operation) }\end{array}$ \\
\hline Duty Cycle & $\begin{array}{l}\text { Adjustable: } 1 \% \text { to } 100 \% \\
\text { (with } 1 \% \text { precision) }\end{array}$ \\
\hline $\begin{array}{l}\text { Number of output } \\
\text { phases }\end{array}$ & Single-phase, and three-phase \\
\hline $\begin{array}{l}\text { Single-phase/Control } \\
\text { techniques }\end{array}$ & $\begin{array}{l}\text { Phase-shifted, PWM with } \\
\text { adjustable pulse number k (k:1-10), } \\
\text { SPWM (Demo) }\end{array}$ \\
\hline $\begin{array}{l}\text { Three-phase/Control } \\
\text { techniques }\end{array}$ & $\begin{array}{l}120^{\circ} \text { conduction angle, } \\
180^{\circ} \text { conduction angle }\end{array}$ \\
\hline
\end{tabular}

\section{DESIGN AND IMPLEMENTATION}

\section{A. Hardware design}

The hardware consists of a specially designed microcontroller-based control circuit and the user interface units, which are integrated into a commercial rectifier-inverter cascade (Semiteach power unit). In the hardware design, the 


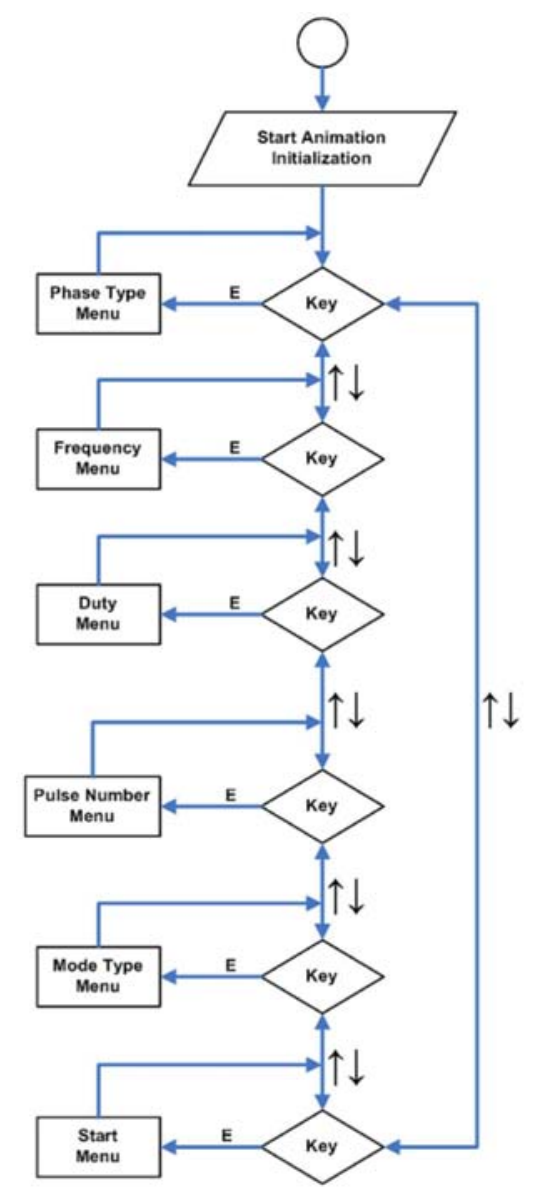

Fig. 3. Main menu flowchart.

components of the control circuit and the user interface unit (LCD, keypad and microcontroller) are chosen to be low cost and easy to find. For the microcontroller, a PIC18F452 has been chosen. This microcontroller has sufficient memory $(32 \mathrm{~kb})$ for the mentioned applications and can operate at up to a frequency of $40 \mathrm{MHz}$. The detailed circuit diagram of the main controller board is given in Appendix A. The LCD and the keypad are placed on the printed circuit board (PCB) of the control system to obtain a compact, user friendly system design.

\section{B. Software implementation}

In this section, the basic controller tasks are explained with the corresponding flowcharts of the implemented control algorithms. Emphasis is given to the main functions of the controller. Once the system is powered on, the system control mode is chosen. If the user chooses the hardware control, experiments can be performed by using the menu flow diagrams given in Fig.3. Process parameters can be set according to main menu flowchart using the LCD and the keypad. After the parameters are set, the user goes through the start menu. The process modes such as phase-shifted PWM, single-phase PWM, SPWM, three-phase $120^{\circ}$ conduction angle, and threephase $180^{\circ}$ conduction angle modes are processed in the software according to the flowcharts given in Figures 4 - 8, respectively. In all of the processes, there is an initialization

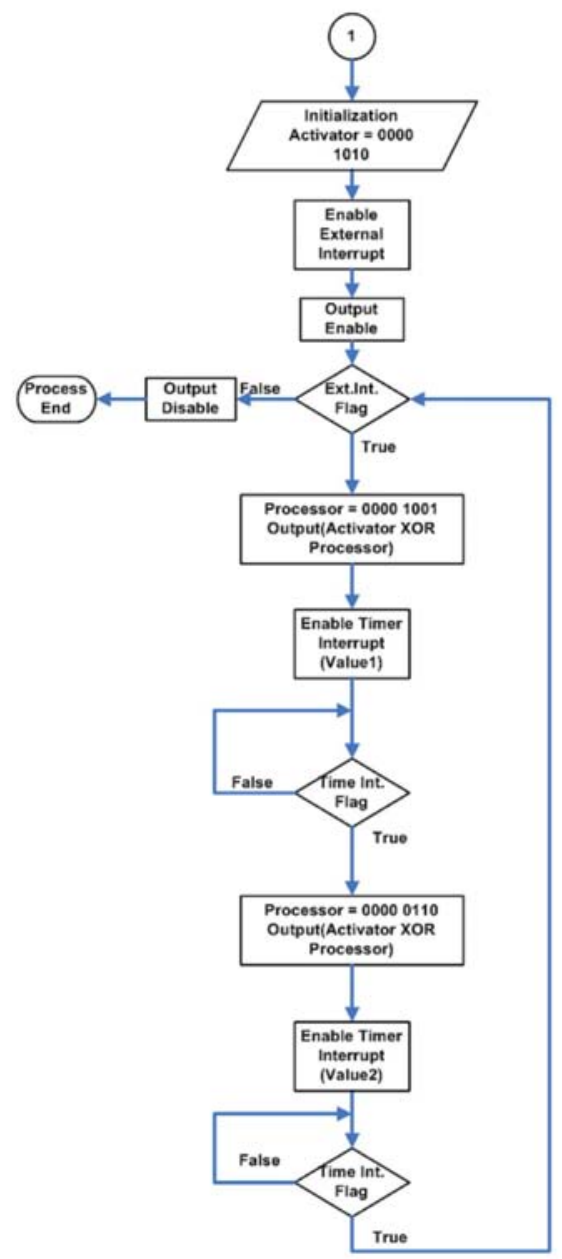

Fig. 4. Flowchart of the phase shifted PWM control.

part. In this part, the necessary calculations are done with the required parameters. After the initialization, the switching signals are generated in an infinite loop. All these processes stop when an external interrupt comes. The switching signal timing is managed by an internal timer interrupt of the microcontroller.

\section{User interface}

The user interface on a personal computer (PC) provides the engineering development and test environment. The environment transfers the required data and controls the chosen processes. Also, by using this environment, the expected signal waveforms of the switch and inverter outputs can be displayed. This feature can be used as a preliminary work for the experiments. Students can observe the expected signal waveforms theoretically by using this feature. After the system is powered on, the type of system control is selected. If the user chooses software control, experiments can be performed using the graphical user interface on the $\mathrm{PC}$, as shown in Figure 9. The user interface given in Figure 9 is created using the MATLAB program [7]. The aim of the designed user interface is to make the set-up user friendly for students.

All of the processes and their parameters are collected on a single page. By using the "Graphics" button in the 


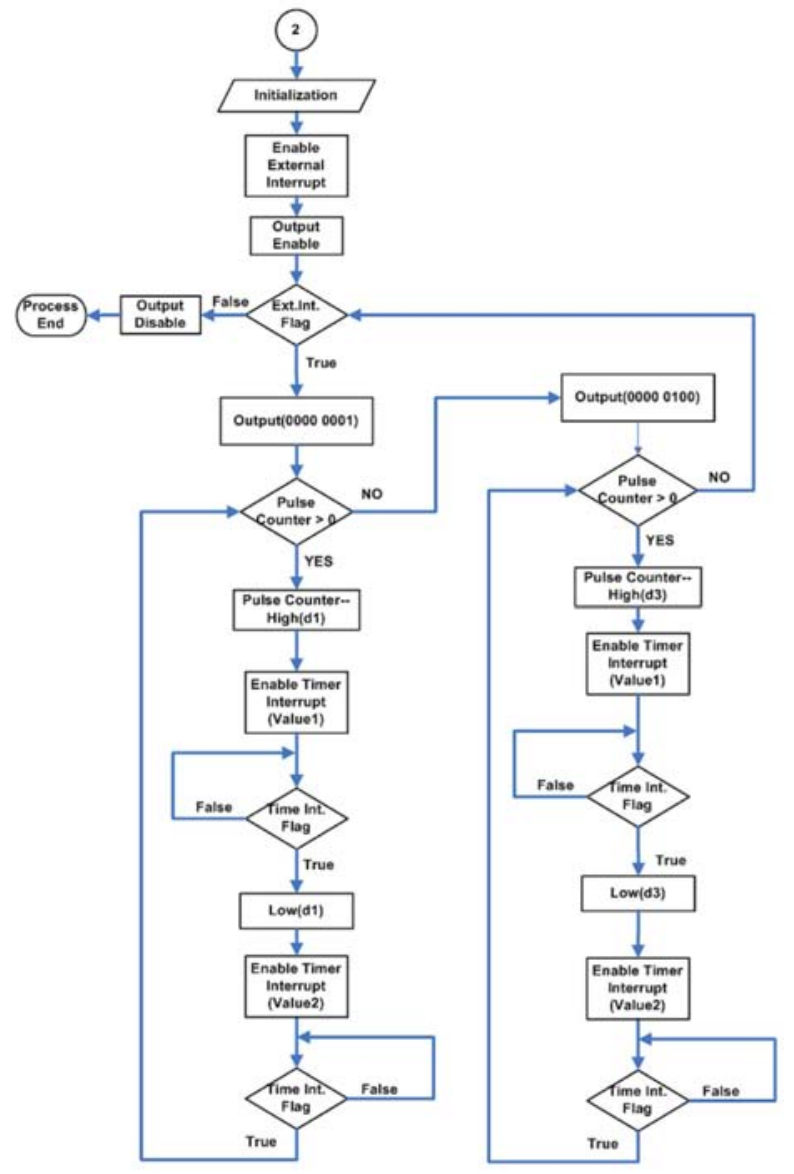

Fig. 5. Single-phase PWM process flowchart.

process box, the related switching signals, and the inverter output signals are generated according to the set parameter values. This feature of the experimental set-up gives students the opportunity to examine the resulting signal waveforms without dealing with the hardware complexity. This kind of preliminary work improves the theoretical and practical abilities of the students. Fig. 10 and 11 depict PWM and SPWM signals which are generated by the user interface.

The "MCU CONTROL" window is designed for software control. In this window, the "SET" button is used to set the desired parameters of the processes. The "START" and "STOP" buttons are used to control the processes, by means of a RS232 communication line.

\section{LABORATORY SET-UP AND EXPERIMENTAL WORK}

Various experiments can be performed with the developed experimental set-up. These are single-phase inverter experiments with uniform PWM, phase-shifted PWM, sinusoidal PWM, and three-phase inverter experiments with $120^{\circ}$ and $180^{\circ}$ conduction angle techniques. Furthermore, via modifications in the software of the microcontroller, it is also possible to extend the application areas of the set-up to wider ranges, up to a $20 \mathrm{kVA}$ power level, for graduate level studies.

In this section, the results of the single-phase PWM, phaseshifted PWM and SPWM switching techniques are given as

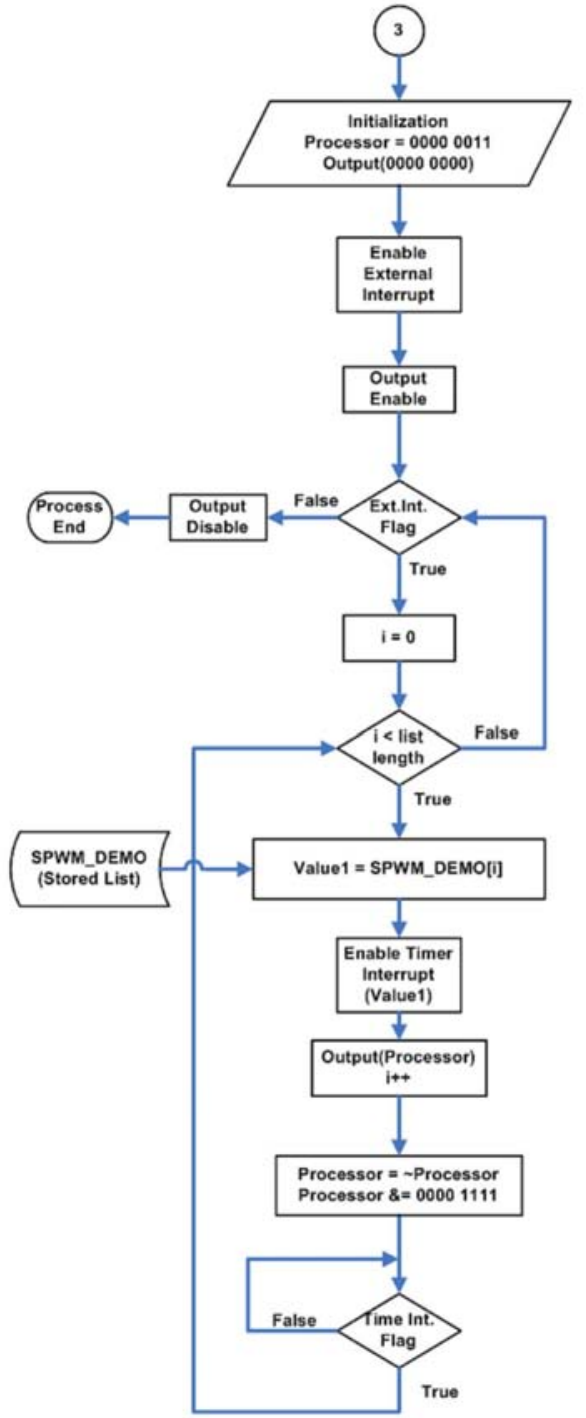

Fig. 6. SPWM process flowchart.

sample cases. In these experiments, the hardware control user interface has been employed. The complete experimental setup is shown in Figure 12. In the single-phase full bridge inverter circuit experiment, first the switching signals (T1, T2, $\mathrm{T} 3, \mathrm{~T} 4)$ are generated and monitored on the oscilloscope for the phase-shifted PWM technique, as shown in Figure 13. For this sample experiment, the frequency is set to $1000 \mathrm{~Hz}$ and the duty cycle to $50 \%$. Fig. 13 depicts the corresponding switching signals obtained in accordance with the theory. The next step in the experiment is to produce the inverter output voltage and the current waveforms with the generated switching signals. For this purpose, the input source voltage $\left(V_{d}\right)$ is set to $50 \mathrm{~V}$ and a single-phase resistive- inductive (R-L) load is used.

Fig. 14 shows the corresponding output voltage and current waveforms. Similarly, the experimental results for single-phase PWM and SPWM can be generated, as illustrated respectively in Figures 15-18. A sample laboratory experiment which can be successfully conducted using this set-up is given in Appendix $\mathrm{B}$ and the corresponding photographs taken during laboratory work are in Appendix C. 


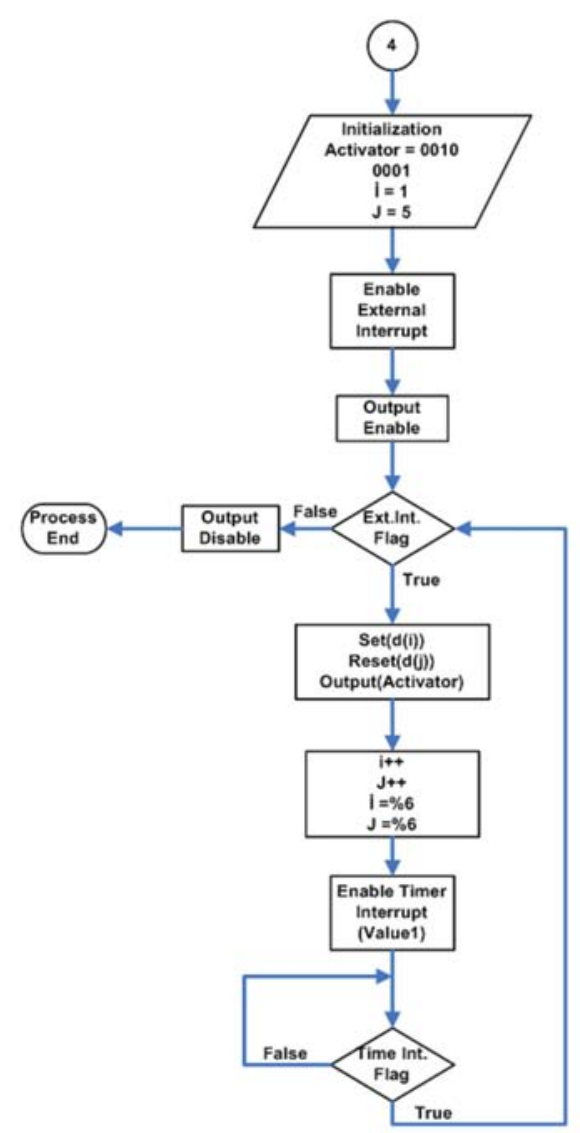

Fig. 7. Three-phase $120^{\circ}$ conduction angle process flowchart.

\section{CONCLUSiOnS}

In this research and development work, a general purpose inverter set-up has been developed for power electronics laboratory experiments. It consists of a complete experimental set-up with an integrated Semiteach IGBT converter system, a microcontroller-based control unit, and alternative user interfaces. This experimental set-up can be used in laboratories either equipped with computers or not. The implemented setup is made of low-cost items and is a versatile, user friendly tool for students in dc-to-ac converter based experiments. The developed system makes the application of different control techniques to single and three-phase inverter circuits easy in power electronics laboratory environments. It reduces the complexity of inverter experiments and gives students the opportunity to perform different applications by themselves. This is accomplished by simple choices of switching strategies from menus via a LCD and keypad. Such a set-up eliminates the extensive work required for the power circuit layout, control functions, gate drive circuits, isolation, etc., which are quite difficult to fulfill for both undergraduate and graduate level students. Thus, the developed set-up both contributes to undergraduate experiments and constitutes an infrastructure for different applications at the graduate level. Another major drawback of commercially available teaching sets is that in general they adopt a 'black-box' approach, with only access to the output terminals. In that case, it is difficult for students to understand the operation of the built-in power converters

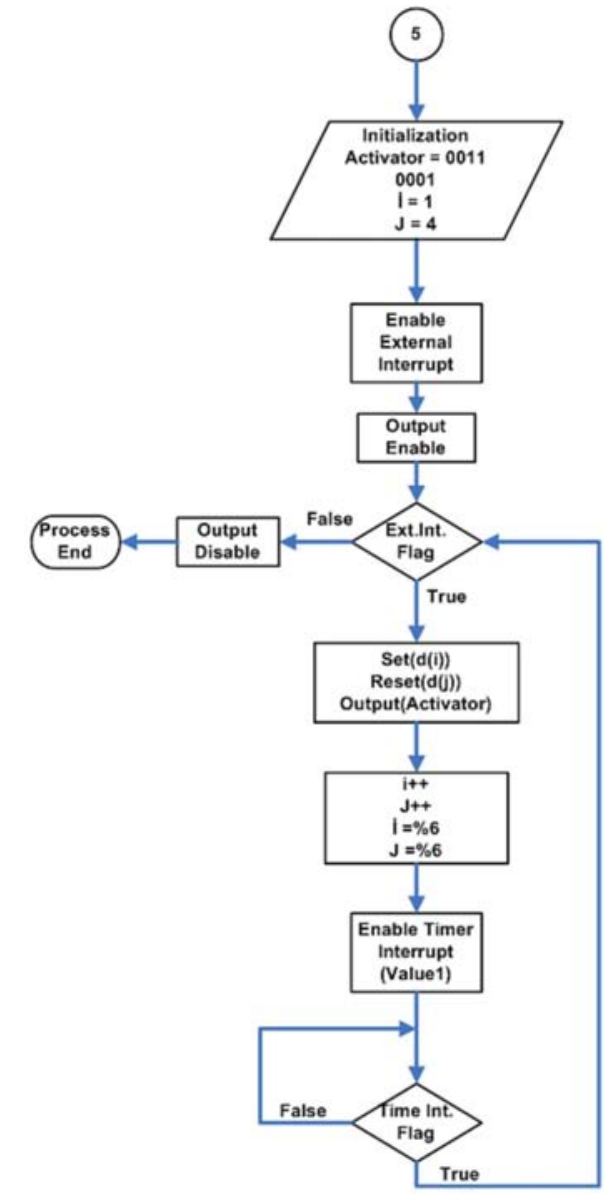

Fig. 8. Three-phase $180^{\circ}$ conduction angle process flowchart.

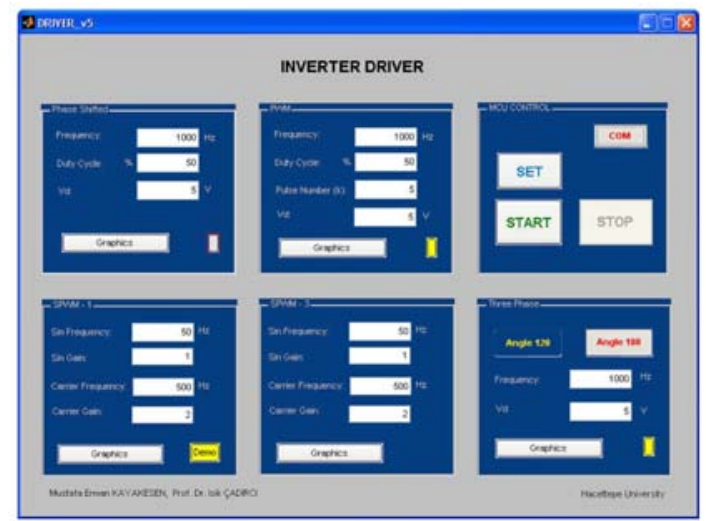

Fig. 9. User interface.

during a laboratory experiment. The developed system however, is very informative in the sense that all of the power and control circuits are user accessible and observable from outside.

\section{APPENDIX}

\section{A. Detailed circuit diagram}

The circuit diagram of the implemented microcontrollerbased hardware is given in Fig. 19. The output signals T1T6 represent the switching signals generated by the microcontroller according to the user defined settings. 


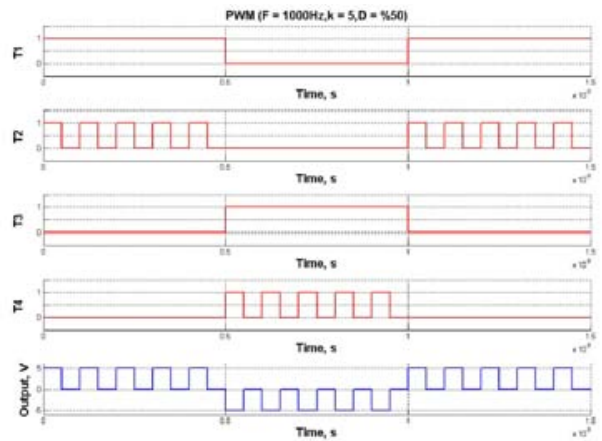

Fig. 10. PWM switching signals and the inverter output voltage (1: On, 0: Off).

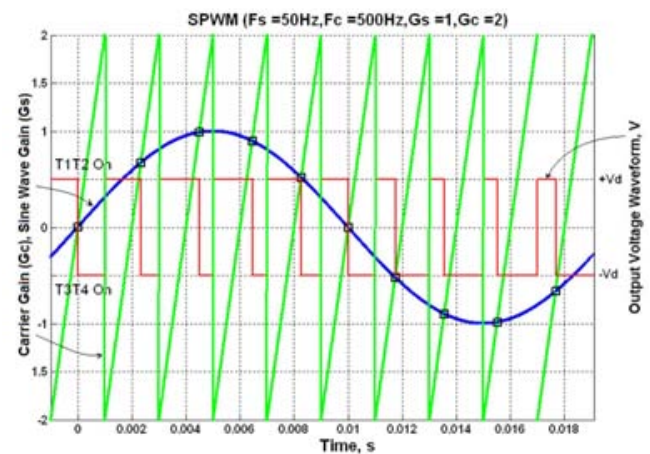

Fig. 11. SPWM switching signals and the inverter output voltage.

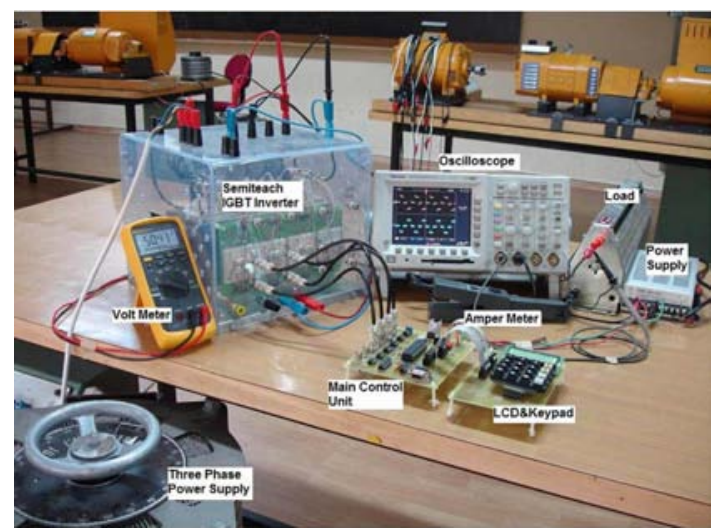

Fig. 12. Complete experimental set-up.

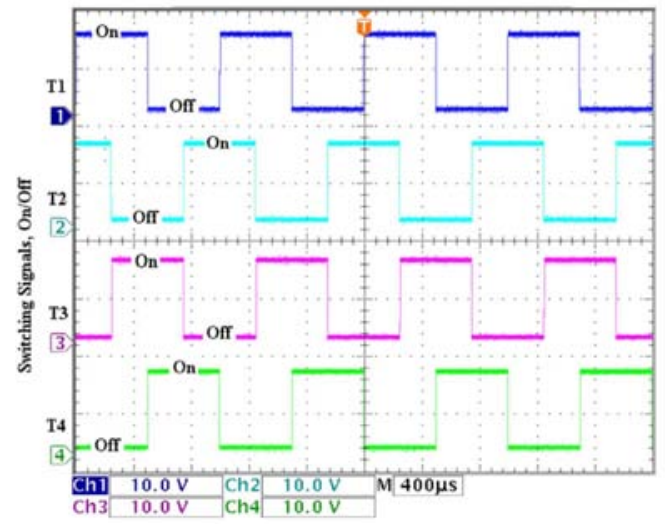

Fig. 13. Phase-shifted PWM switching signals.

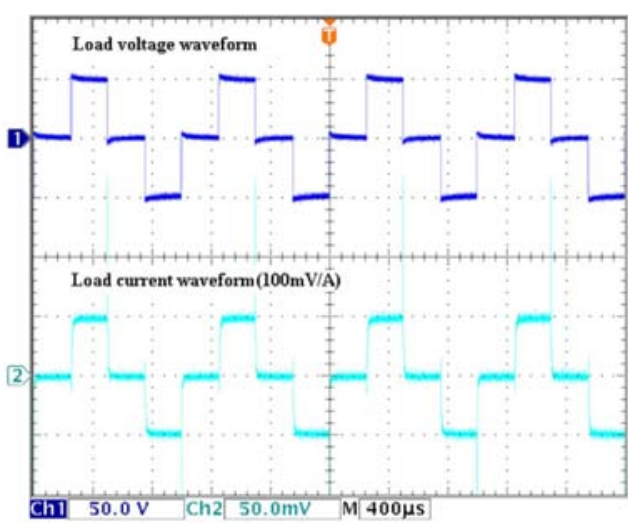

Fig. 14. Phase-shifted PWM load voltage and current waveforms.

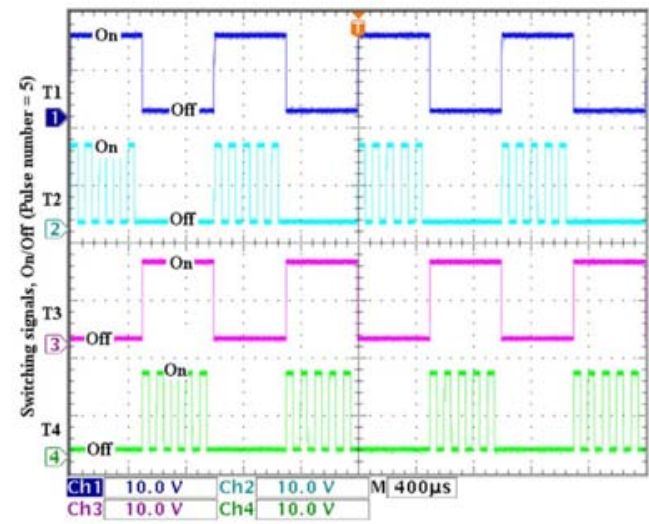

Fig. 15. Single-phase PWM switching signals.

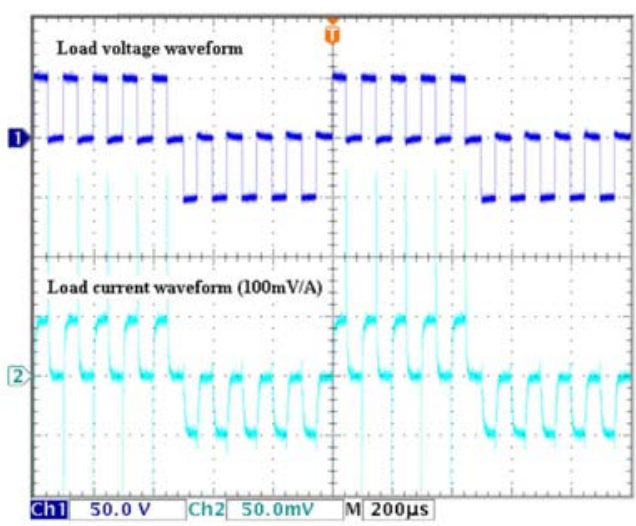

Fig. 16. Single-phase PWM load voltage and current waveforms.

\section{B. Sample Experiment:}

\section{Phase-Shifted PWM Switching Technique in Inverters}

\section{a. Objective}

This is a single-phase full bridge inverter circuit experiment. In this experiment the phase-shifted PWM switching technique will be implemented using the "Computer/Microcontroller Based General Purpose Inverter Control Experimental Set Up."

First, the switching signals are generated, and then, these signals are used to drive the IGBTs in the Semiteach Power Unit. The corresponding inverter output voltage and current waveforms will be investigated. Computer simulations of the 


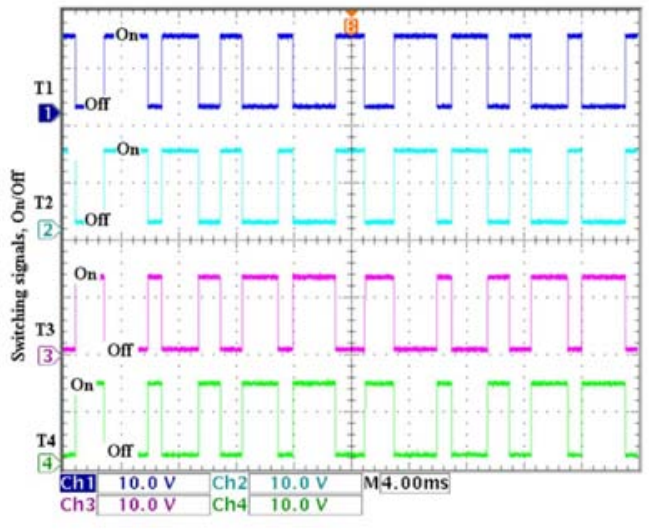

Fig. 17. SPWM switching signals.

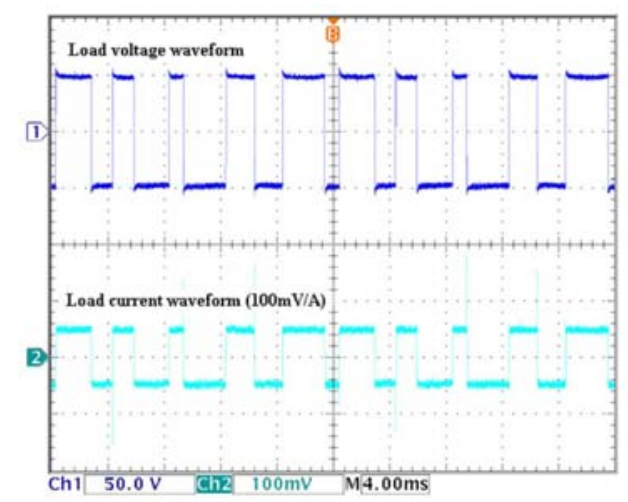

Fig. 18. SPWM load voltage and current waveforms.

experiment will be carried out as a preliminary work. For this purpose, the Simplorer V6 circuit simulation program [8] will be used.

\section{b. Preliminary Work}

1) Design a circuit in Simplorer for the phase-shifted PWM switching technique.

i. Define the simulation parameters as given in Fig. 20.

ii. Take the input voltage $V_{d}$ as $50 \mathrm{~V}$.

iii. Use a $100 \Omega$ resistive load.

iv. Use model based SKM50GB123D IGBTs for switching transistors with $0.22 \mu \mathrm{F}$ snubbers.

2) Create switching signals for the phase-shifted switching technique. The required parameters are set as follows:

i. Frequency $(\mathrm{Hz})=1000$.

ii. Duty cycle $(\%)=50$.

3) Save the current and voltage waveforms of the load.

i. Calculate the RMS value of the output voltage.

ii. Add an inductance $(\mathrm{L}=3.45 \mathrm{mH})$ in series with the resistive load and save the current and voltage waveforms of the load.

\section{c. Experimental Work}

1) Set up the experimental set. Use a LCD and keypad to control the system.

2) Give the dc power to the control unit $\left(V_{d c}=15 \mathrm{~V}\right)$.

3) Set the frequency to $1000 \mathrm{~Hz}$ and the duty cycle to $50 \%$.

4) Choose the single-phase and phase-shifted modes using a LCD and keypad.
5) Start the process. Observe the switching signals (T1 to T4).

6) Stop the process.

7) Connect the switching signals to the Semiteach Power Unit. Be careful to connect the switching signals in the correct order (Fig. 21).

8) Choose a $100 \Omega$ resistor as a load.

9) Start the process again.

10) Give the ac power to the experimental set from a variac and increase the input voltage from zero until the dc link voltage $\left(V_{d}\right)$ is about $50 \mathrm{~V} \mathrm{dc}$.

11) Observe the output voltage and current waveforms on the oscilloscope and save the waveforms to memory.

12) Repeat (8-11) for an inductive load.

\section{d. Results and Conclusion}

1) Compare the switching signals obtained from the simulations with the experimental ones. Comment on the differences between the simulation and experimental results.

2) Compare the inverter output waveforms obtained from the simulations with the experimental ones. Comment on the differences between the simulation and experimental results. Measure the RMS values and compare them with the theoretical ones. Comment on the results.

3) Comment on the preliminary work (3) results.

e. Equipment List

1) Oscilloscope, associated voltage and current probes.

2) DC power supply (15 V).

3) Three phase power supply (from variac).

4) Semiteach IGBT converter unit.

5) Computer/Microcontroller based general purpose inverter control set-up.

6) Resistor: $1 \times 100 \Omega$.

7) Inductor: $1 \times 3.45 \mathrm{mH}$.

8) AVO meter.

\section{f. Sample Experiment Report}

1) The designed circuit for the Simplorer simulation is shown in Fig. 22. Similar simulations can be carried out via the developed PC-based user interface as explained in Section III.

2) The switching signal simulation results are shown in Fig. 23 and the associated experimental results are given in Fig. 24. By using the oscilloscope features, the duty cycle and frequency data can be obtained. The duty cycle and frequency values are depicted in the figures. As seen from these figures, the simulation and experimental results obtained are very similar.

3) In this part, the load voltage and current waveforms of the simulation (Fig. 25) and experimental results (Fig. 26) are compared with each other. Although switching transients affect the experimental waveforms, it is observed that the results are very close to each other.

4) If an inductive load $(\mathrm{L}=3.45 \mathrm{mH})$ is added in series with the resistive load, the resultant waveforms are obtained as given in Fig. 27 and 28. The inductive load effect is observed from the change in the current waveform as exponential rises and decays. 


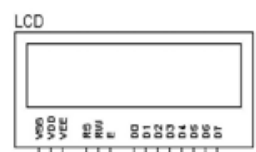

$-\infty n+\infty+\infty=20=$

$\Delta \Delta \Delta \Delta \Delta \Delta \Delta \Delta \Delta \Delta \Delta$

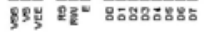

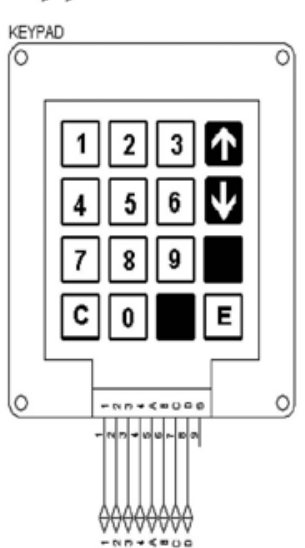

$\mathrm{Ul}: \mathrm{PICl} 18 \mathrm{~F} 452$

U2: MAX232

U3: 74LS240

U4-U9: LF 351

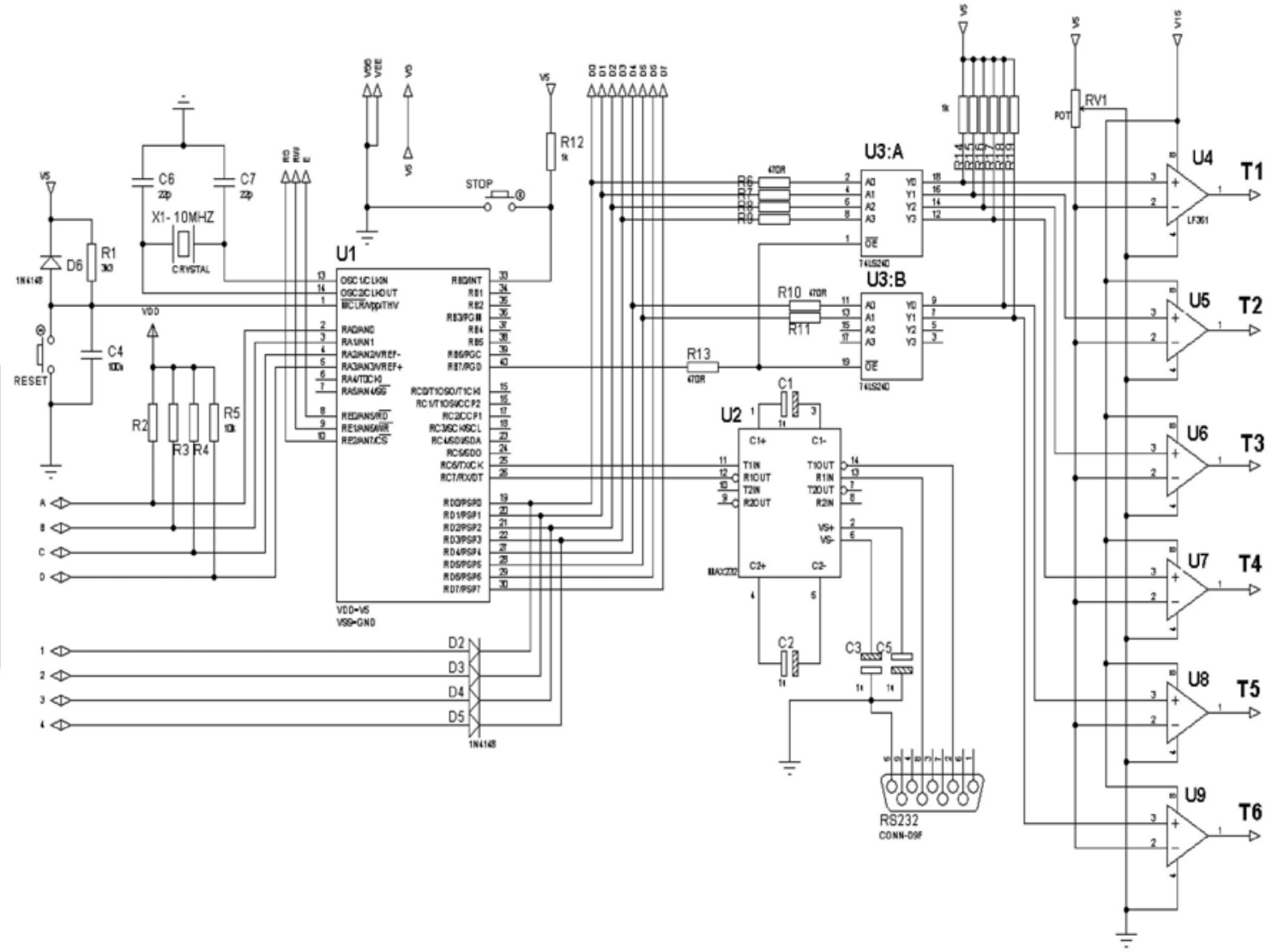

Fig. 19. Detailed circuit diagram of the controller hardware.

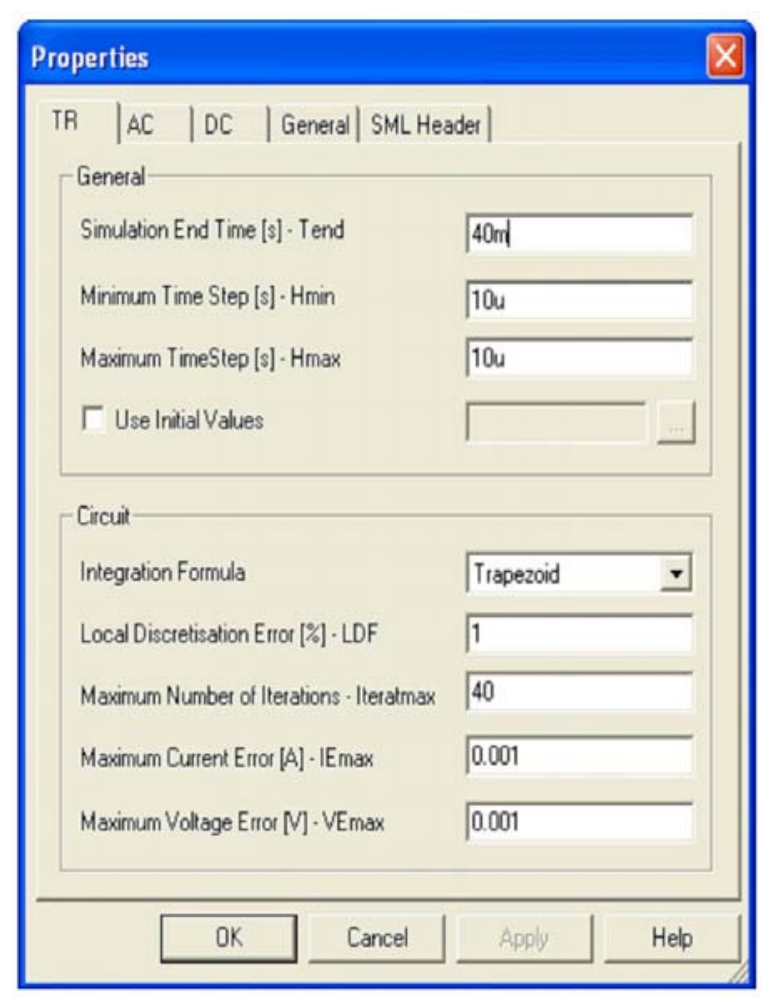

Fig. 20. Simplorer simulation parameters.

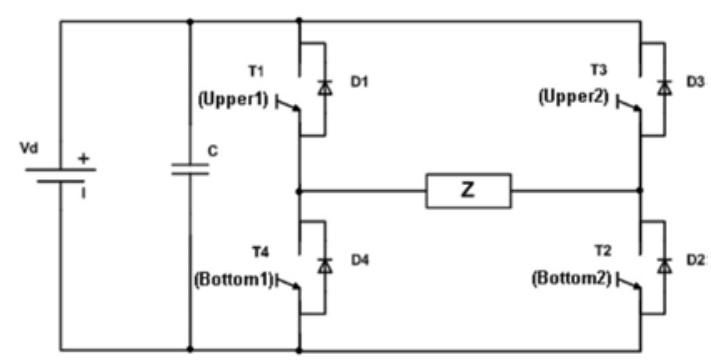

Fig. 21. Single-phase full bridge circuit.

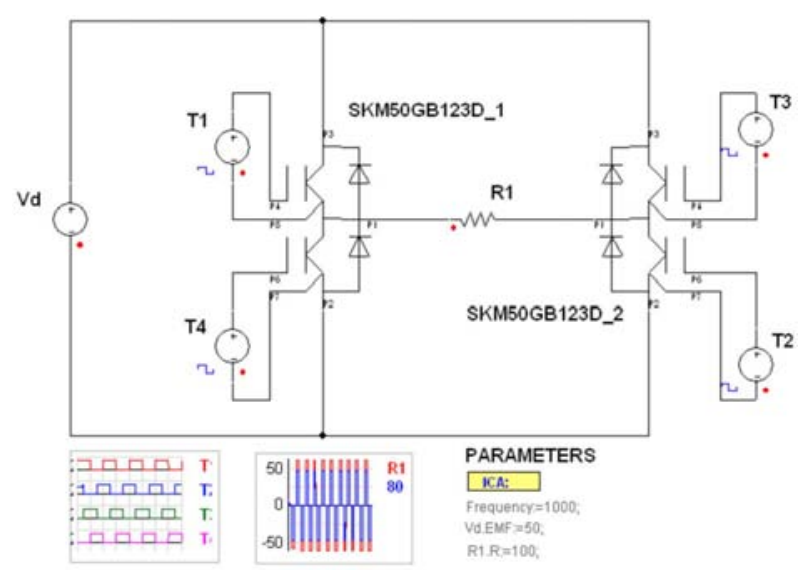

Fig. 22. Simplorer simulation circuit. 


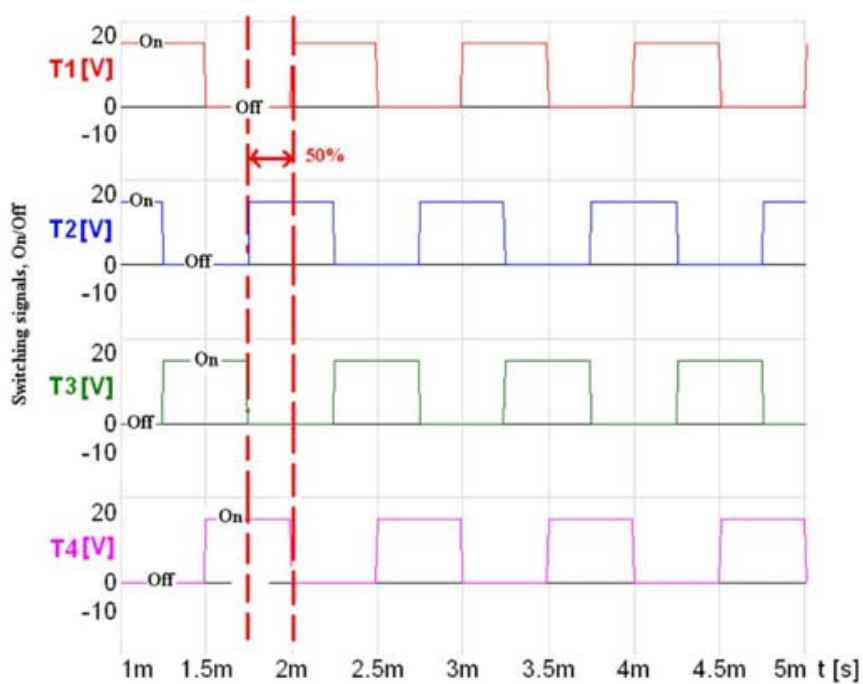

Fig. 23. Simulation results of phase shifted PWM switching signals.

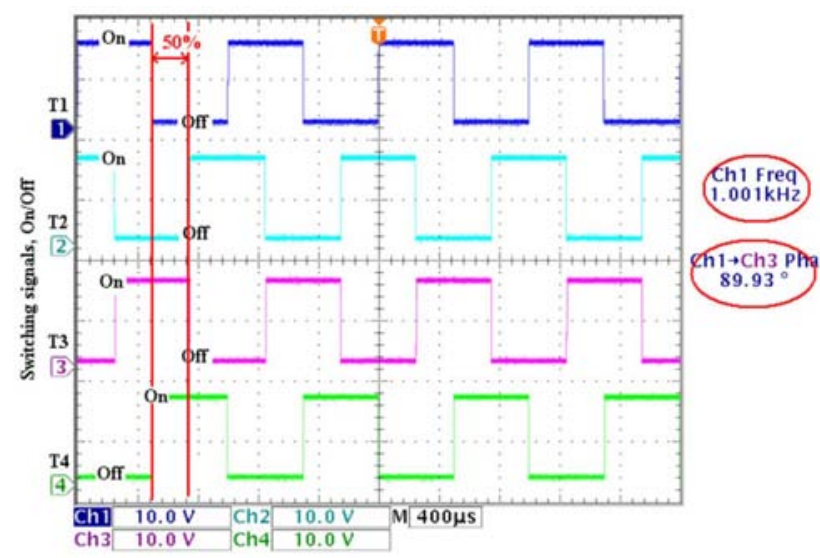

Fig. 24. Experimental results of phase shifted PWM switching signals.

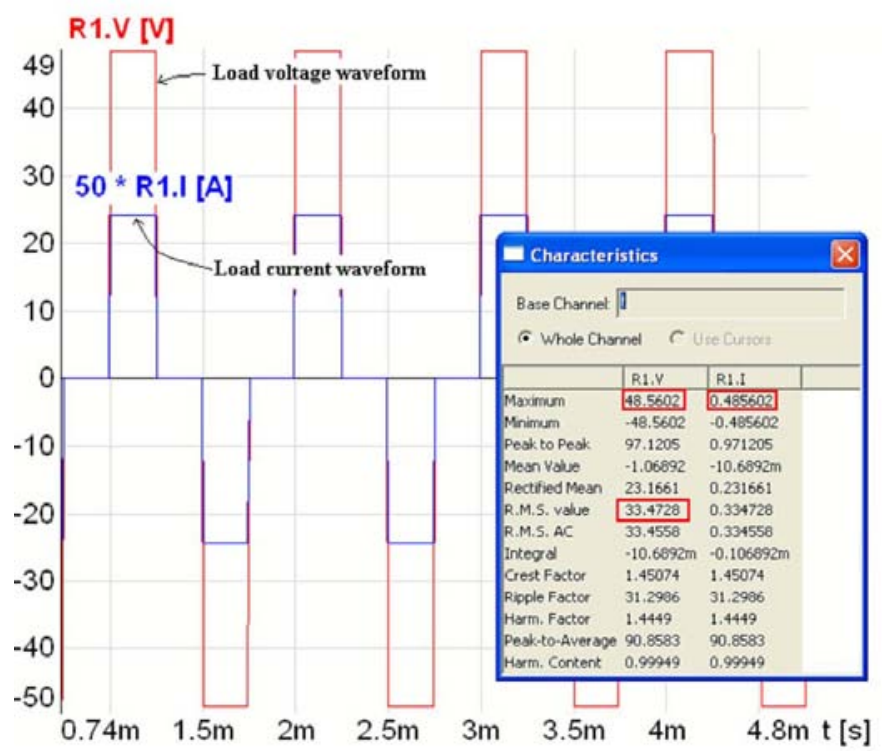

Fig. 25. Simulation results of phase-shifted PWM load voltage and current waveforms with resistive load.

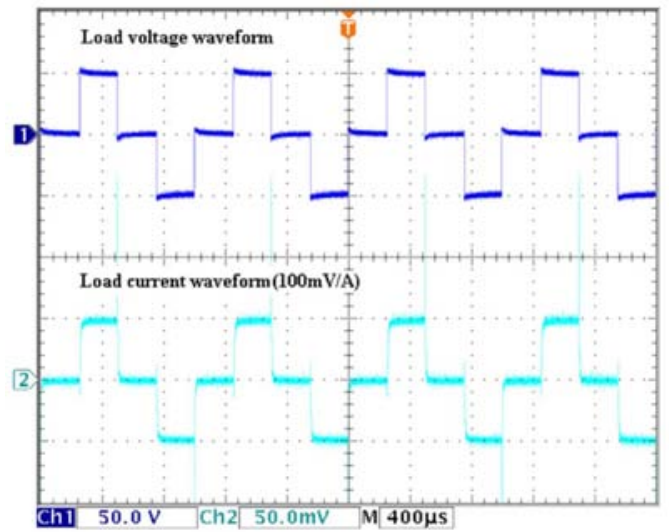

Fig. 26. Experimental results of phase-shifted PWM inverter load voltage and current waveforms with resistive load.

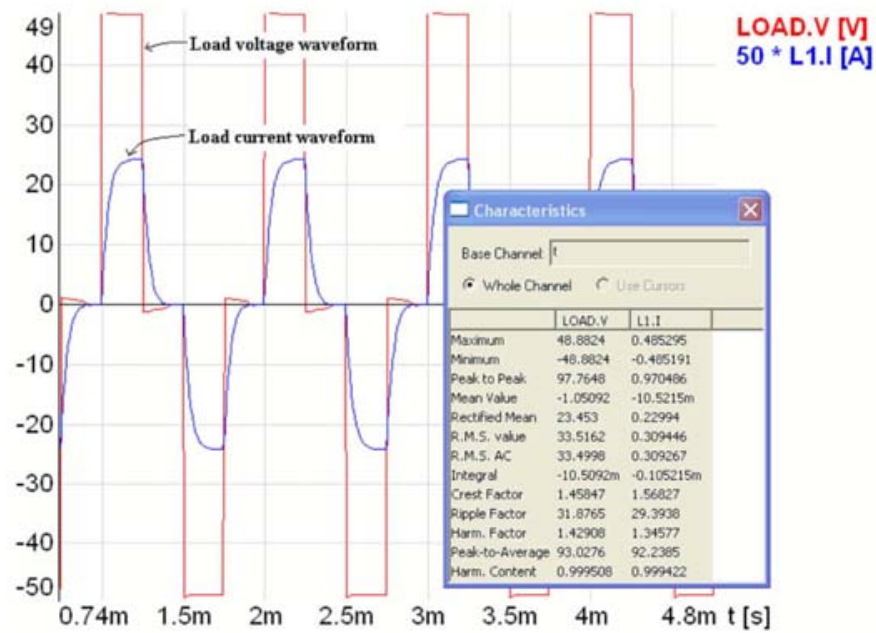

Fig. 27. Simulation results of phase-shifted PWM inverter load voltage and current waveforms with R-L load.

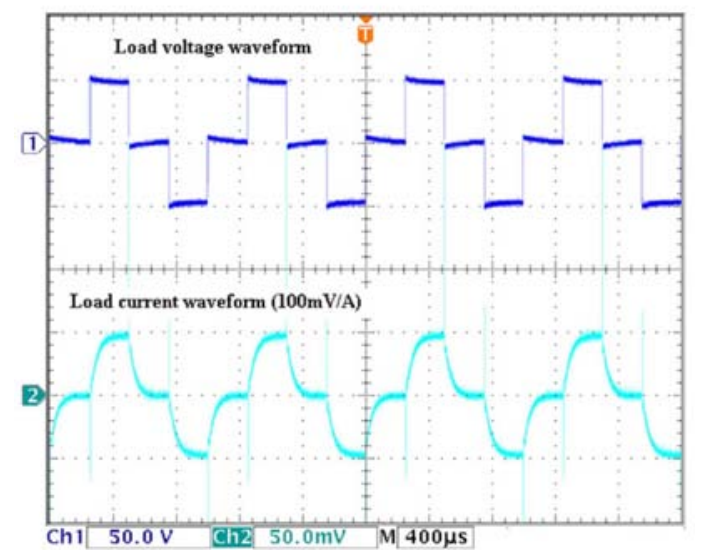

Fig. 28. Experimental results of phase-shifted PWM inverter load voltage and current waveforms with R-L load. 


\section{Photographs During Laboratory Work}

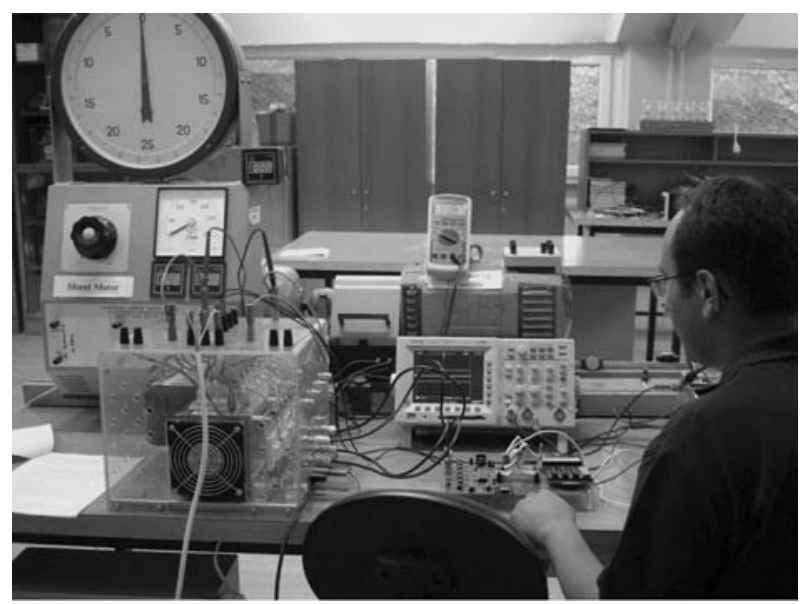

(a) Front view.

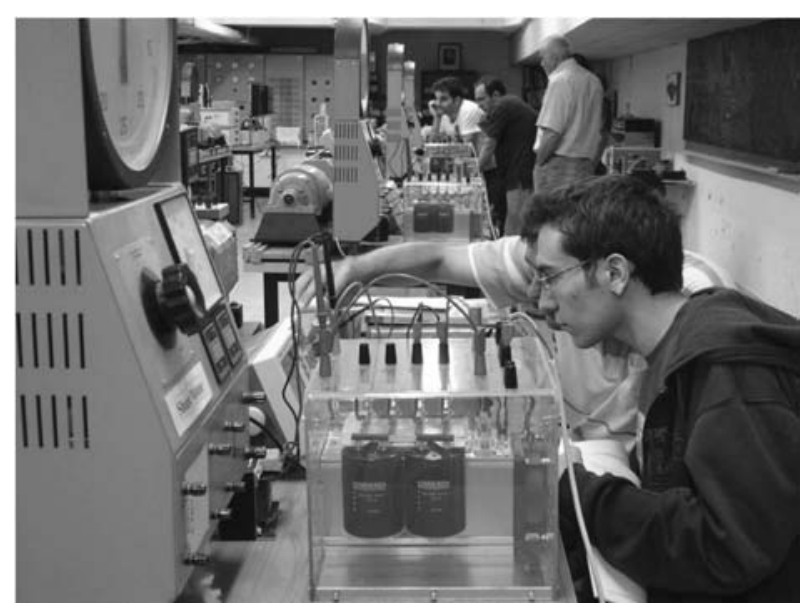

(b) Laboratory view.

Fig. 29. Experimental work in the laboratory.

\section{REFERENCES}

[1] Torrey D. A., "A project-oriented power electronics laboratory," IEEE Transactions on Power Electronics, Vol. 9, No. 3, pp. 250-255, May 1994.

[2] Jimenez-Martinez J. M., Soto F., Esther de Jodar, Villarejo J. A., RocaDorda J., "A New Approach for Teaching Power Electronics Converter Experiments," IEEE Transactions on Education, Vol. 48, No.3, pp. 513519, Aug. 2005.

[3] Fernandez C., Garcia O., Cobos J. A., Uceda J., "Self-learning Laboratory Set-up For Teaching Power Electronics Combining Simulations and Measurements," in Proceedings of Power Electronics Specialists Conference(PESC 2002), Vol. 2, pp. 449-454, 2002.

[4] Sangswang A., Rost G., Nwankpa C. O., "A Modular Simulink-Based Controlled Three- Phase Switch Mode Inverter," Proceedings of Power Engineering Society Summer Meeting, Vol. 4, pp. 2101-2106, 2000.

[5] Shirsavar S. A., Potter B. A., Ridge I. M. L., "Three-Phase Machines and Drives-Equipment for a Laboratory-Based Course," IEEE Transactions on Education, Vol. 49, No. 3, pp. 383-388, Aug. 2006.

[6] SEMITEACH: Demonstrating Power Electronics Available at: http://www.semikron.es/seminew/noticias/pdf/n_semiteach.pdf, Feb. 2005.

[7] The MathWorks, Inc., Getting Started with MATLAB, Version 7, 2004.

[8] Ansoft Corp.,SIMPLORER(TM) simulation system, Version 6, 2002.

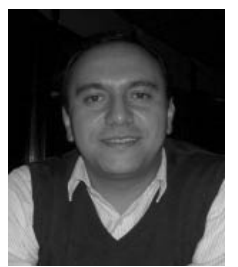

Mustafa Erman Kayakesen received his M.Sc. in Electrical and Electronics Engineering from Hacettepe University (HU), Ankara, Turkey, in 2007. He is currently a Design Engineer at the Turkish Aerospace Industry (TAI), Ankara, Turkey. His current areas of interest include microcontroller based circuits and power converters.

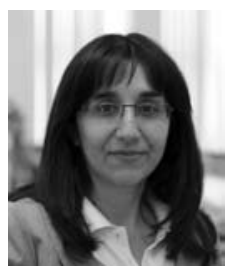

Isik Çadirci received her B.Sc., M.Sc., and Ph.D. in Electrical and Electronics Engineering from the Middle East Technical University (METU), Ankara, Turkey, in 1987, 1988, and 1994, respectively. She is currently a Professor of Electrical and Electronics Engineering at Hacettepe University, Ankara, Turkey, and also the Head of the Power Electronics Department, TUBITAK Uzay Research Institute, the Scientific and Technological Research Council of Turkey (TUBITAK), Ankara. Her current areas of interest include electric motor drives, switch-mode power supplies, and power quality. 